\title{
Development of Surgical Treatment for Vitreous Disease
}

\author{
Tatsuya Mimura ${ }^{1}$, Hidetaka Noma ${ }^{2}$, Hideharu Funatsu ${ }^{2}$ \\ ${ }^{1}$ Department of Ophthalmology, Tokyo Women's Medical University Medical Center East, Tokyo, Japan \\ ${ }^{2}$ Department of Ophthalmology, Yachiyo Medical Center, Tokyo Women's Medical University, Yachiyo, Japan \\ Email: mimurat-tky@umin.ac.jp
}

Received September 4, 2012; revised October 3, 2012; accepted October 12, 2012

\begin{abstract}
Vitreous surgery has improved remarkably with various advances in surgical instruments and techniques. The two most important breakthrough in recent years have been the introduction of small-gauge pars plana vitrectomy (PPV) systems and new illumination devices. Compared with traditional 20-gauge PPV, sutureless small-gauge PPV appears to be safer, with a shorter operating time, less postoperative inflammation, less patient discomfort, and more rapid recovery of visual acuity. This article reviews recent progress in the surgical management of vitreous disease with a historical perspective.
\end{abstract}

Keywords: Review; Vitrectomy; 25 Gauge

\section{Introduction}

The eye has an anterior cavity and a posterior (vitreous) cavity. The vitreous cavity is the larger of the two and it contains a transparent medium known as the vitreous fluid or vitreous body. This is a unique, spherical, transparent structure that entirely fills the posterior cavity of the eye, and is bounded by the retina, pars plana, and lens (Figure 1). Changes in the structure of the vitreous with aging can cause vitreous liquefaction or detachment and vitreoretinal diseases such as epiretinal membrane, macular hole, and incidental vitreoretinal hemorrhage. Pars plana vitrectomy (PPV) is commonly performed to resect the affected vitreous in patients with such vitreoretinal diseases.

In the early 1970s, the first PPV procedure was described by Machemer, who used a 17-gauge (17-G) cut ter $[1,2]$. Subsequently, O'Malley and Heintz introduced

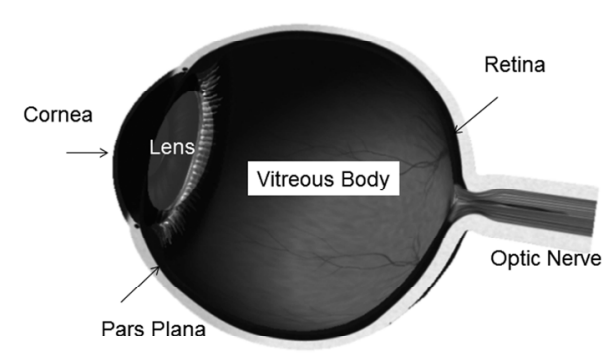

Figure 1. Structure of the eye. The vitreous body occupies the cavity behind the lens and in front of the retina. The figure was drawn with a drafting system (iCeye, Mimir Sun-Bow, Tokyo, Japan). a three-port 20-G canular entry system in 1975 [3], while De Juan introduced 25-G instruments in 1990 [4]. Over the last decade, there has been development of $23-G[5,6]$, 25-G [7-9], and 27-G [10,11] transconjunctival sutureless vitrectomy devices. The latest innovations have led to reduction of the surgical wound size, which achieves more rapid wound stabilisation, and enables surgeons to perform PPV more easily and safely.

This review describes the latest advances that have been made in the performance of PPV based on recent reports and reviews [12-17]. A review of articles published up to January 2012 was undertaken using the PubMed database. Papers that were available electronically before publication were also included. Search terms included "vitrectomy", "20 gauge", "23 gauge", "25 gauge", and "27 gauge".

\section{History and Overview of Pars Plana Vitrectomy}

In the 1970s, Machemer et al. first introduced a 17-gauge vitreous cutter $[1,2]$. His vitrectomy method employed a single $17-\mathrm{G}$ port $(1.5 \mathrm{~mm}$ in diameter) and a multifunctional instrument that could both cut and aspirate the vitreous $[1,2]$. The instrument contained a micromotor that rotated cutting mechanism in the tip of the vitreous cutter, along with suction and infusion systems. Therefore, this device was referred to as the vitreous infusion suction cutter (VISC) [18]. It was able to excise formed vitreous, while simultaneously replacing the resected volume with infused saline solution. The intraocular portion of the probe had a very large outer diameter of $2.3 \mathrm{~mm}$, and a 
fiberoptic sleeve that could be placed over the instrument tip in order to provide intraocular illumination.

In 1975, O'Malley introduced a three-port 20-G canular entry system that employed a smaller $20-\mathrm{G}$ vitreous cutter $(0.9 \mathrm{~mm})$ [3]. This three-port PPV system soon became the standard for modern vitreous surgery. With the $20-\mathrm{G}$ vitrectomy technique, the sclerotomy requires suturing, and both the sclerotomy site and the overlying conjunctiva are closed with sutures. Although the guillotine-style probe that was initially used for the early $20-\mathrm{G}$ cutter was very small, it ultimately proved to be entirely unsatisfactory due to inherent problems when cutting the vitreous, in addition to being quite expensive. Also, the non-disposable probes used with this device required complete preoperative sterilization and needed careful attention after each operation. To overcome these disadvantages, a disposable spring-type $20-\mathrm{G}$ vitreous cutter was developed in the early 1980 s. Soon after this, various companies developed the next generation of $20-\mathrm{G}$ cutter and vitrectomy systems, including the Microvit ${ }^{\circledR}$ (Storz Instruments, St. Louis, MO), the Accurus ${ }^{\circledR}$ (Alcon Labs, Fort Worth, TX), and the Millennium ${ }^{\circledR}$ (Bausch \& Lomb, Rochester, NY) (Figure 2).

In 1990, de Juan and Hickingbotham used conventional sclerotomy to develop a $25-\mathrm{G}$ ( $0.5 \mathrm{~mm}$ diameter $)$ vitrectomy system, but it was still necessary to suture the sclerotomy site [4]. During the last decade, modern transconjunctival sutureless $23-\mathrm{G}$ and $25-\mathrm{G}$ vitrectomy systems have been developed. Fujii et al. introduced a 25-G transconjunctival sutureless vitrectomy (25G TSV) system in 2002 [7-9], which Bausch \& Lomb brought to the market in 2001 as the MillenniumTM Transconjunctival Sutureless Vitrectomy System (TSV25). This was followed by Hilton and Eckhart introducing a 23-G system, which combined some of the benefits of both the $25-\mathrm{G}$ and $20-\mathrm{G}$ instrumentation packages $[5,6]$. Subsequently, Oshima et al. developed a self-retaining 27-G system that included an infusion line, a high-speed vitreous cutter, an illumination system, and various vitreoretinal instruments, such as membrane forceps and sharp-tipped endophotocoagulation probes $[10,11]$.

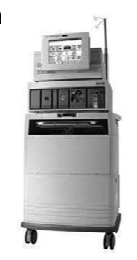

(a)

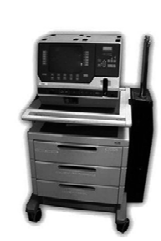

(b)

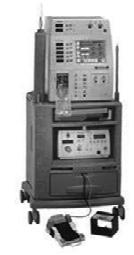

(c)
Figure 2. Vitrectomy systems. (a) Millennium ${ }^{\circledR}$ (Bausch \& Lomb); (b) Microvit Vitrectomy System ${ }^{\circledR}$ (Storz Instruments); (c) Accurus ${ }^{\circledR}$ (Alcon Surgical). Each of these systems is able to perform the following basic functions: aspiration, cutting, infusion, endoillumination, and gas venting.

\section{Vitreous Cutter}

\subsection{Vitreous Cutter Size}

A summary of the vitreous cutters is given in Table 1. The sclerotomy diameter for 20-G, 23-G, and 25-G systems is $0.9,0.7$, and $0.5 \mathrm{~mm}$, respectively (Figure 3 ). Due to the smaller inner diameter and port size, the $23-\mathrm{G}$ and $25-\mathrm{G}$ vitrectors fundamentally have lower aspiration and infusion rates compared with the $20-\mathrm{G}$ vitrector. Although lower cutting rates can potentially lead to vitreoretinal traction that damages the retina, the $25-\mathrm{G}$ highspeed cutter with a very low flow may be more effective for dissecting the vitreous close to the retinal surface.

\subsection{Pneumatic and Electrical Cutters}

There are two types of vitreous cutter available, which are the pneumatic cutter and the electrical cutter. The pneumatic vitreous cutter was first reported by O'Malley and Heintz in 1975 [3]. A pneumatic probe cutter works by intermittently releasing air from a source inside the surgical device to force a vertical guillotine-like blade downward [3]. This design has been widely adopted because it allows smaller and lighter cutters to be made than those with an electric motor in the hand-piece, such as the Millennium TSV25 High-Speed Vitreous CutterTM [19]. Electric probes contain a motor and a camshaft that drives an inner tube. Constant sinusoidal motion of the inner tube produces equal closed and open times independent of the cutting rate.

According to Bausch \& Lomb, their new high-speed vitrectomy electric cutter based on the TSV25 system cuts at 1500 times per minute and generates a 50\% higher aspiration flow rate than 25-G pneumatic cutters [19]. However, many vitreous surgeons prefer a pneumatic cutter because disposable pneumatic cutters weigh much less than electric cutters, thereby reducing fatigue.

\subsection{Aspiration and Infusion Rates of Vitreous Cutters}

The 25-G vitrector has lower aspiration and infusion rates compared with the $20-\mathrm{G}$ cutter because of its smaller port size and inner diameter [7]. Flow rates are influenced by various factors such as the type of substance being removed (e.g., fluid, blood clot, or proliferative tissue), the cutting rate, and the inner diameter of the vitrector [13,20,21].

In general, a higher cutting rate means that less fluid and tissue enter the port with each cut [7-19]. According high-speed cutter is set at $500 \mathrm{mmHg}$ and 1500 cuts per minute (cpm), the average flow rate is $40 \%$ greater than that for a $20-\mathrm{G}$ pneumatic cutter operated at $250 \mathrm{mmHg}$ to Bausch \& Lomb, when the Millennium 25-G and 750 cpm [19]. Thus, if the same settings were used for 
Table 1. Summary of Vitreous Cutters by Hubschman [22,23].

\begin{tabular}{|c|c|c|c|c|c|c|c|c|}
\hline \multirow{3}{*}{$\begin{array}{l}\text { Vitreous Cutter } \\
\text { (Model\#) }\end{array}$} & \multirow{3}{*}{ Vitrectomy Consol } & \multirow{3}{*}{ Probe (Gauge) } & \multirow{3}{*}{$\begin{array}{l}\text { Vacuum } \\
\text { (mmHg) }\end{array}$} & \multirow{3}{*}{$\begin{array}{c}\text { Maximum } \\
\text { Rate } \\
\text { (cuts/min) }\end{array}$} & \multirow{3}{*}{$\begin{array}{l}\text { Pneumatic } \\
\text { Action }\end{array}$} & \multicolumn{3}{|c|}{ Shaft Diameter $(\mu \mathrm{m})$} \\
\hline & & & & & & External Shaft & Inter & Shaft \\
\hline & & & & & & $\begin{array}{l}\text { External } \\
\text { Diameter }\end{array}$ & $\begin{array}{c}\text { Inner } \\
\text { Diameter }\end{array}$ & $\begin{array}{l}\text { Outer } \\
\text { Diameter }\end{array}$ \\
\hline $\begin{array}{c}\text { Alcon }^{\mathrm{a}} \\
(\# 8065740253)\end{array}$ & Accurus $800^{\mathrm{a}}$ & $20-\mathrm{G}$ & 250 & 2500 & Pneumatic & 900 & 475 & 640 \\
\hline $\begin{array}{l}\text { Bausch \& Lomb }{ }^{b} \\
\quad \text { (\#CX5825) }\end{array}$ & Millennium $^{\mathrm{b}}$ & $20-\mathrm{G}$ & 250 & 1500 & Electric & $870 / 730$ & 400 & - \\
\hline $\begin{array}{l}\text { Bausch \& Lomb }{ }^{b} \\
\quad \text { (\#DP4803) }\end{array}$ & Millennium $^{\mathrm{b}}$ & $20-\mathrm{G}$ & 250 & 750 & Pneumatic & 880 & 441 & - \\
\hline $\operatorname{Midlabs}^{\mathrm{d}}(\# 2540 \mathrm{E})$ & Millenium ${ }^{\mathrm{b}}+{ }^{\mathrm{e}} \mathrm{AVE}$ & $20-\mathrm{G}$ & 250 & 2500 & Pneumatic & 910 & 510 & 650 \\
\hline $\begin{array}{c}\text { Alcon }^{\mathrm{a}} \\
(\# 806570821)\end{array}$ & Accurus $800^{\mathrm{a}}$ & $23-\mathrm{G}$ & 550 & 2500 & Pneumatic & 630 & 355 & 460 \\
\hline $\begin{array}{c}\text { DORC }^{\mathrm{c}} \\
(\# 1226 \mathrm{NMD} 06)\end{array}$ & Accurus $800^{\mathrm{a}}$ & $23-\mathrm{G}$ & 550 & 2500 & Pneumatic & 590 & 410 & 490 \\
\hline $\begin{array}{c}\text { Alcon }^{\mathrm{a}} \\
(\# 8065750220)\end{array}$ & Accurus 800 & $25-\mathrm{G}$ & 550 & 1500 & Pneumatic & 500 & 227 & - \\
\hline $\begin{array}{l}\text { Bausch \& Lomb }{ }^{b} \\
\quad(\# \text { CX5825) }\end{array}$ & Millennium $^{\mathrm{b}}$ & $25-\mathrm{G}$ & 550 & 1500 & Electric & 500 & 247 & - \\
\hline $\begin{array}{c}\text { DORC }^{\mathrm{c}} \\
(\# 1226 \mathrm{NMD} 05)\end{array}$ & Millenium $^{\mathrm{b}}$ & $25-\mathrm{G}$ & 550 & 750 & Pneumatic & 490 & 291 & - \\
\hline $\operatorname{Midlabs}^{\mathrm{d}}(\# 2540 \mathrm{E})$ & Millenium ${ }^{\mathrm{b}}+{ }^{\mathrm{e}} \mathrm{AVE}$ & $25-\mathrm{G}$ & 550 & 2500 & Pneumatic & 500 & 292 & 370 \\
\hline
\end{tabular}

${ }^{\mathrm{a}}$ Alcon Surgical, Forth Worth, TX. ${ }^{\mathrm{b}}$ Storz Millennium Microsurgical System, Bausch \& Lomb, St Louis, MO. ${ }^{\mathrm{c}}$ Dutch Ophthalmic USA, Kingston, NH. ${ }^{\mathrm{d}}$ Mid-

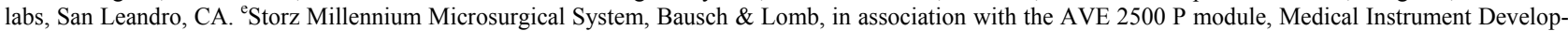
ment Labs Inc. (Midlabs).
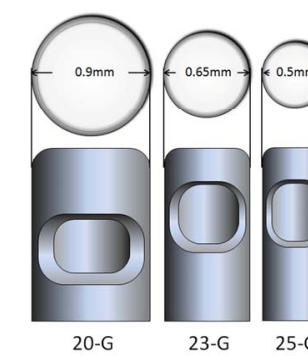

(a)

(b)

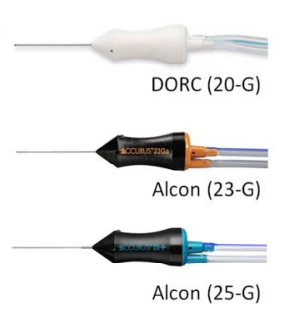

(c)

Figure 3. Comparison of 20-G, 23-G, and 25-G vitreous cutters. Both the 23-G and 25-G cutters have the cutter opening closer to the tip of the probe.

both $20-\mathrm{G}$ cutters, the high-speed electric cutter would remove the vitreous $88 \%$ more rapidly than the pneumatic cutter [7].

Magalhães et al. evaluated the flow rates of porcine vitreous and balanced saline solution (BSS) achieved with different vitrectomy systems [20]. Using a 20-G electric system, vitreous was removed more rapidly and there was less resistance at faster cutting rates. With the 23-G pneumatic system, a reduced duty cycle and incomplete aperture opening at $1500 \mathrm{cpm}$ resulted in a low vitreous flow $(0.0001 \mathrm{~mL} / \mathrm{s}$ at $500 \mathrm{mmHg})$. When set at
$500 \mathrm{mmHg}$ of suction a $25-\mathrm{G}$ electric cutter showed higher average flow rates at high cutting rates $(600 \mathrm{cpm}$ : $0.004 \mathrm{~mL} / \mathrm{s} ; 1500 \mathrm{cpm}: 0.013 \mathrm{~mL} / \mathrm{s}$ ) compared with a 25-G pneumatic cutter, which demonstrated a decrease of flow cut speeds higher than $1,000 \mathrm{cpm}(1000 \mathrm{cpm}: 0.015$ $\mathrm{mL} / \mathrm{s} ; 1500 \mathrm{cpm}: 0.006 \mathrm{~mL} / \mathrm{s}$ ) [20].

The constant duty cycle electric drive mechanism employs a constant BSS flow that results in increased vitreous flow as the cutting speed increases. In contrast, the pneumatic drive mechanism has a reduced duty cycle at high speeds [20]. Since flow rates tend to vary among different vitreous cutters of the same gauge set at the same cutting rate and vacuum level, this suggests that the flow rate can also be affected by the duty cycle, cutting port area, and internal shaft diameter [20-26].

Hubschman et al. compared the flow rates of water and egg white using 20-G, 23-G, and 25-G systems and found that the flow rates were the highest with the 20-G system, followed by the 23-G and 25-G systems [22]. They also evaluated the flow rate of porcine vitreous using 20-G, 23-G, and 25-G pneumatic vitreous cutters and found that flow was correlated with the internal shaft surface area [23]. Moreover, they found that the opening and closing phases of vitreous cutters that use the latest 
pneumatic actuation technology were longer than those of earlier cutters, resulting in a better duty cycle and better flow rates [23].

Fang et al. reported that the new generation of pneumatic $25-\mathrm{G}$ cutters achieve higher water flow rates at higher cutting speeds, maintain relatively constant vitreous flow rates as the cutting speed increases, and have a higher duty cycles at all cutting speeds compared with the current generation of electrical cutters [24]. They concluded that the high and relatively constant vitreous flow rates achieved by the new cutters were due to maintenance of a high duty cycle when the cutting speed was increased. In addition, more efficient vitreous flow was seen with the smaller diameter cutters, which could match or exceed those for the larger diameter cutters by optimizing the duty cycle.

Teixeira et al. used fresh porcine eyes to quantify the vitreous traction created by pneumatic (20-G, 23-G, and $25-\mathrm{G})$ and electric cutters (20-G and 25-G) and found that the 20-G, 23-G, and 25-G pneumatic cutters caused traction ranging from 2.06 to 37.22 dynes, 3.85 to 15.38 dynes, and 5.13 to 27.91 dynes, respectively [26]. For the $20-\mathrm{G}$ and $25-\mathrm{G}$ electric cutters, they found that traction ranged from 3.60 to 41.78 dynes and 5.28 to 27.91 dynes, respectively. Thus, retinal traction increased with stronger aspiration and with closer proximity to the retina, while retinal traction decreased at higher cutting rates, so they concluded that these three factors (aspiration, distance from the retina, and cutting rate) were crucial with regard to the retinal traction created by a vitreous cutter.

Because the 25-G vitreous cutters have a small opening, higher infusion and aspiration rates are required in order to dissect the vitreous body. Typical settings for small-gauge vitrectomy are in the range of 1200 to 2500 cpm, 35 to $50 \mathrm{mmHg}$ for infusion, and up to $600 \mathrm{mmHg}$ for aspiration [7-27]. It is now possible to perform vitrectomy with a cutting rate of up to $5000 \mathrm{cpm}$ by using the latest vitrectomy system from Alcon.

\subsection{Cutting Port and Shaft}

The size and position of the cutting port also affect the flow rate and efficiency of aspiration. The port of 23-G and $25-\mathrm{G}$ cutters is smaller than that of Alcon's 20-G cutter ( $56 \%$ and $31 \%$ of the $20-\mathrm{G}$ size, respectively). The smaller port combined with the higher cutting rate of the $25-\mathrm{G}$ cutter results in weaker aspiration, so the $25-\mathrm{G}$ cutter is safer for peripheral vitreous dissection close to the retina. Compared with the $20-\mathrm{G}$ cutter, the port is located closer to the tip of the probe in the $25-\mathrm{G}$ cutter. This is advantageous for peripheral shaving of the vitreous base and segmentation or delamination of proliferative tissue.

Because of their thinness, the 23-G and 25-G probes are less rigid than the 20-G probe [22]. Hubschman et al. reported that even cutters of the same gauge show differences of rigidity. This can be explained by differences in the properties of the metals used, the thickness of the shaft walls, and the length of the probe [22]. Although shorter probes are more rigid than longer probes, they are not suited for highly myopic eyes with a longer axial length. Rigid vitreous instruments are advantageous in a variety of situations, including the dissection of proliferative tissue, shaving peripheral vitreous, or removing a dislocated intraocular lens. Low rigidity can be a serious problem, especially when using a $27-\mathrm{G}$ probe. After Oshima et al. shortened the shaft of the 25-G Alcon probe from $32 \mathrm{~mm}$ to $25 \mathrm{~mm}$, they succeeded in creating a $27-G$ cutter that has similar rigidity to the $25-\mathrm{G}$ cutter [11]. In addition, after shortening the shaft, they were still able to successfully perform peripheral vitrectomy using the 27-G system in eyes with axial lengths ranging from 22 to $28 \mathrm{~mm}$.

\section{Illumination System}

In the early 1970s, an external slit lamp located outside the eye was first used for vitrectomy. To achieve the insertion of a fiberoptic light source into the eye, Peyman developed a prototype illumination device for a threeport vitrectomy in 1976 [28]. Subsequent development of small diameter wide-angle endoillumination probes made it possible to obtain a wide panoramic view of the surgical field $[29,30]$. With the $20-\mathrm{G}$ vitrectomy systems, a halogen light source is commonly used for illumination. When a halogen light was used for illumination with the $25-\mathrm{G}$ system, however, it only achieved about $40 \%$ of the brightness of the 20-G system.

In 2003, Eckardt developed a xenon-based illumination probe that was designed to directly penetrate the conjunctiva and sclera [31]. As the xenon light source is brighter than a halogen light source, illumination is no longer an issue for the $25-\mathrm{G}$ system. Recently, several other xenon illuminators have been developed, such as Xenon (Alcon Labs., Fort Worth, TX), Photon (Synergetics Inc., O'Fallon, MO) and BrightStar (DORC, Zuidland, The Netherlands) (Figure 4). Alcon's new Constellation system has much brighter illumination than the original Xenon light. To support 27-G vitrectomy, Eckardt et al. developed a $27-\mathrm{G}$ illumination system in 2008 [32],

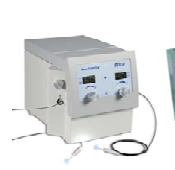

(a)

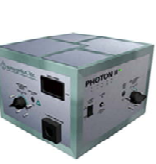

(b)

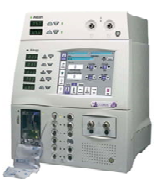

(c)
Figure 4. Xenon illuminators. (a) Photon 2 (Synergetics); (b) BrightStar (DORC); (c) Xenon illuminator and Accurus $^{\circledR}$ vitrectomy system (Alcon Surgical). 
while Oshima et al. also developed 27-G and 29-G illumination systems in the same year [10-33]. Subsequently, Synergetics released a much brighter mercury vapor lamp (Photon 2; Synergetics), while Oshima et al. further developed a 29-G illuminator that was based on mercury vapor, and which emitted twice as much light as the 29-G xenon-based probe [33].

\section{Wide-Field and Endoscopic Systems}

Other surgical instruments and innovations have been developed for vitreous surgery, including a vitrectomy system that uses endoscopic visualization, a wide-field viewing system, an endolaser system, and various illumination systems, all of which have facilitated the treatment of vitreoretinal diseases that were previously difficult or even impossible to manage surgically. Wide-angle viewing systems and endoscopy provide the vitreous surgeon with a clear view of the peripheral retina and vitreous base.

There are two kinds of wide-angle viewing systems, which are classified as contact lens and noncontact systems. Contact lens systems provide a wider field of view with less aberration and reflection because the lens is directly attached to the cornea with a viscous agent. Contact lens systems include those produced by Advanced Visual Instruments, Inc. (New York), Volk Optical, Inc. (Mentor, Ohio), and Ocular Instruments, Inc. (Bellevue, Wash). Noncontact systems employ a flexible arm to position a wide-angle lens that can be easily moved in and out of the surgical field. Noncontact systems include the Resight 700 (Carl Zeiss Meditec AG, Jena, Germany), SuperView Tornambe Contact Lens (Insight Instruments, Inc.), Binocular Indirect Ophthalmo Microscope (BIOM; Oculus, Wetzlar, Germany), Optical Fiber Free Intravitreal Surgery System (OFFISS; Topcon Medical Systems, Oakland, NJ), and Peyman-WesselsLanders 132D Upright Vitrectomy Lens (PWL; Ocular Instruments, Bellevue, WA).

In patients with corneal opacities, small pupil, hyp hema, cataract, and posterior capsule opacity, endoscopic vitrectomy is an optional procedure. It is difficult to remove the vitreous by standard three-port pars plana vitrectomy due to poor visualization of the anterior segment. Wide-angle viewing systems and endoscopic vitrectomy have revolutionized such vitrectomy procedures and surgeons can now easily remove the peripheral vitreous thanks to these advances.

\section{Surgical Materials for Vitreous Surgery}

Surgical materials such as perfluorocarbon liquid, silicone oil, perfluoropropane (C3F8) gas, and sulfur hexafluoride (SF6) gas, as well as ocular visco-elastic substances have also facilitated safer removal of abnormal tissue with concurrent reduction of intraocular damageand have made vitreous surgery more efficient. To enhance visualization of the vitreous, epiretinal membrane, and internal limiting membrane, various staining materials can be used, including indocyanine green (ICG) [3437], trypan blue (TB) [35-40], triamcinolone acetonide (TA) (Tognetto 2005) [41], and brilliant blue G (BBG) $[42,43]$.

\section{Summary}

This review highlighted the latest innovations in vitreous surgery. Significant advances have been made in the development of small-gauge PPV systems, and vitrectomy through a $0.5 \mathrm{~mm}$ incision is now feasible. By the application of optimal techniques, surgeons can improve the surgical outcome, thereby improving the vision and the quality of life of their patients.

\section{REFERENCES}

[1] R. Machemer, "A New Concept for Vitreous Surgery. 2. Surgical Technique and Complications," American Journal of Ophthalmology, Vol. 74, No. 6, 1972, pp. 10221033.

[2] R. Machemer and E. W. Norton, "A New Concept for Vitreous Surgery. 3. Indications and Results," American Journal of Ophthalmology, Vol. 74, No. 6, 1972, pp. 1034-1056.

[3] C. O'Malley and R. M. Heintz Sr., "Vitrectomy with an Alternative Instrument System," American Journal of Ophthalmology, Vol. 7, No. 4, 1975, pp. 585-588, 591584.

[4] E. de Juan Jr. and D. Hickingbotham, "Refinements in Microinstrumentation for Vitreous Surgery," American Journal of Ophthalmology, Vol. 109, No. 2, 1990, pp. 218-220.

[5] G. F. Hilton, R. G. Josephberg, L. S. Halperin, S. A. Madreperla, D. A. Brinton, S. S. Lee and S. F. Gordon, "Office-Based Sutureless Transconjunctival Pars Plana Vitrectomy," Retina, Vol. 22, No. 6, 2002, pp. 725-732. doi:10.1097/00006982-200212000-00007

[6] C. Eckardt, "Transconjunctival Sutureless 23-Gauge Vitrectomy," Retina, Vol. 25, No. 2, 2005, pp. 208-211. doi:10.1097/00006982-200502000-00015

[7] G. Y. Fujii, E. De Juan Jr., M. S. Humayun, D. J. Pieramici, T. S. Chang, C. Awh, E. Ng, A. Barnes, S. L. Wu and D. N. Sommerville, "A New 25-Gauge Instrument System for Transconjunctival Sutureless Vitrectomy Surgery," Ophthalmology, Vol. 109, No. 10, 2002, pp. 18071813.

[8] G. Y. Fujii, E. De Juan Jr., M. S. Humayun, T. S. Chang, D. J. Pieramici, A. Barnes and D. Kent, "Initial Experience Using the Transconjunctival Sutureless Vitrectomy System for Vitreoretinal Surgery," Ophthalmology, Vol. 109, No. 10, 2002, pp. 1814-1820. doi:10.1016/S0161-6420(02)01119-3 
[9] K. G. Au Eong, G. Y. Fujii, J. E. de Jr., P. S. Jensen, D. N. Sommerville, T. H. Shelley, A. C. Barnes and M. Maia, "A New Three-Port Cannular System for Closed Pars Plana Vitrectomy," Retina, Vol. 22, No. 1, 2002, pp. 130132. doi:10.1097/00006982-200202000-00032

[10] Y. Oshima, C. C. Awh and Y. Tano, "Self-Retaining 27Gauge Transconjunctival Chandelier Endoillumination for Panoramic Viewing during Vitreous Surgery," American Journal of Ophthalmology, Vol. 143, No. 1, 2007, pp. 166-167. doi:10.1016/j.ajo.2006.07.051

[11] Y. Oshima, T. Wakabayashi, T. Sato, M. Ohji and Y. Tano, "A 27-Gauge Instrument System for Transconjunctival Sutureless Microincision Vitrectomy Surgery," Ophthalmology, Vol. 117, No. 1, 2010, pp. 93-102. doi:10.1016/j.ophtha.2009.06.043

[12] E. Chen, "25-Gauge Transconjunctival Sutureless Vitrectomy," Current Opinion in Ophthalmology, Vol. 18, No. 3, 2007, pp. 188-193. doi:10.1097/ICU.0b013e328133889a

[13] S. K. Warrier, R. Jain, J. S. Gilhotra and H. S. Newland, "Sutureless Vitrectomy," Indian Journal of Ophthalmology, Vol. 56, No. 6, 2008, pp. 453-458. doi:10.4103/0301-4738.43364

[14] M. J. Spirn, "Comparison of 25, 23 and 20-Gauge Vitrectomy," Current Opinion in Ophthalmology, Vol. 20, No. 3, 2009, pp. 195-199. doi:10.1097/ICU.0b013e328329eaea

[15] T. Sandinha, C. de Souza, R. Essex, T. L. Kelly, S. Lake and R. Phillips, "Revisiting Transconjunctival Sutureless 25-Gauge Vitrectomy: Still Worthwhile?" Clinical \& Experimental Ophthalmology, Vol. 37, No. 7, 2009, pp. 649-653. doi:10.1111/j.1442-9071.2009.02116.x

[16] F. M. Recchia, I. U. Scott, G. C. Brown, M. M. Brown, A. C. Ho and M. S. Ip, "Small-Gauge Pars Plana Vitrectomy: A Report by the American Academy of Ophthalmology," Ophthalmology, Vol. 117, No. 9, 2010, pp. 1851-1857. doi:10.1016/j.ophtha.2010.06.014

[17] I. D. Fabian and J. Moisseiev, "Sutureless Vitrectomy: Evolution and Current Practices," British Journal of Ophthalmology, Vol. 95, No. 3, 2011, pp. 318-324. doi:10.1136/bjo.2009.176495

[18] P. E. Cleary, "The Treatment of Advanced Diabetic Eye Disease," Irish Journal of Medical Sciences, Vol. 148 No. S2, 1979, pp. 38-44.

[19] B. D. McCary, C. S. Daniel and K. H. Edwards, "System Enhancements Bring Added Safety, Efficiency and Easeof-Use to 25-Gauge Vitrectomy," Bausch \& Lomb Incorporated, SU-4024, 2004.

[20] O. Magalhaes Jr., L. Chong, C. De Boer, P. Bhadri, R. Kerns, A. Barnes, S. Fang and M. Humayun, "Vitreous Dynamics: Vitreous Flow Analysis in 20-, 23-, and 25-Gauge Cutters," Retina, Vol. 28, No. 2, 2008, pp. 236241. doi:10.1097/IAE.0b013e318158e9e 0

[21] O. Magalhaes Jr., M. Maia, A. Maia, F. Penha, E. Dib, M. E. Farah and P. Schor, "Fluid Dynamics in Three 25Gauge Vitrectomy Systems: Principles for Use in Vitreoretinal Surgery," Acta Ophthalmologica, Vol. 86, No. 2, 2008, pp. 156-159.

doi:10.1111/j.1600-0420.2007.00988.x
[22] J. P. Hubschman, A. Gupta, D. H. Bourla, M. Culjat, F. Yu and S. D. Schwartz, "20-, 23-, and 25-Gauge Vitreous Cutters: Performance and Characteristics Evaluation," Retina, Vol. 28, No. 2, 2008, pp. 249-257. doi:10.1097/IAE.0b013e31815ec2b3

[23] J. P. Hubschman, J. L. Bourges, I. Tsui, S. Reddy, F. Yu and S. D. Schwartz, "Effect of Cutting Phases on Flow Rate in 20-, 23-, and 25-Gauge Vitreous Cutters," Retina, Vol. 29, No. 9, 2009, pp. 1289-1293. doi:10.1097/IAE.0b013e3181acd3a9

[24] S. Y. Fang, C. M. DeBoer and M. S. Humayun, "Performance Analysis of New-Generation Vitreous Cutters," Graefe's Archive for Clinical and Experimental Ophthalmology, Vol. 246, No. 1, 2008, pp. 61-67. doi:10.1007/s00417-007-0672-8

[25] T. Sato, S. Kusaka, Y. Oshima and T. Fujikado, "Analyses of Cutting and Aspirating Properties of Vitreous Cutters with High-Speed Camera," Retina, Vol. 28, No. 5, 2008, pp. 749-754. doi:10.1097/IAE.0b013e3181631907

[26] A. Teixeira, L. P. Chong, N. Matsuoka, L. Arana, R. Kerns, P. Bhadri and M. Humayun, "Vitreoretinal Traction Created by Conventional Cutters during Vitrectomy," Ophthalmology, Vol. 117, No. 7, 2010, pp. 1387-1392. doi:10.1016/j.ophtha.2009.11.004

[27] T. Altan, N. Acar, Z. Kapran, Y. B. Unver and S. Ozdogan, "Transconjunctival 25-Gauge Sutureless Vitrectomy and Silicone Oil Injection in Diabetic Tractional retinal Detachment," Retina, Vol. 28, No. 9, 2008, pp. 1201-1206. doi:10.1097/IAE.0b013e3181853d3c

[28] G. A. Peyman, "Improved Vitrectomy Illumination System," American Journal of Ophthalmology, Vol. 81, No. 1, 1976, pp. 99-100.

[29] E. H. Ryan Jr., "Two Shielded Bullet' Probes for Panoramic Endoillumination," Archives of Ophthalmology, Vol. 115, No. 1, 1997, pp. 125-126. doi:10.1001/archopht.1997.01100150127028

[30] G. A. Peyman, C. Canakis, C. Livir-Rallatos and J. Easley, "A New Wide-Angle Endoillumination Probe for Use during Vitrectomy," Retina, Vol. 22, No. 2, 2002, p. 242. doi:10.1097/00006982-200204000-00025

[31] C. Eckardt, "Twin Lights: A New Chandelier Illumination for Bimanual Surgery," Retina, Vol. 23, No. 6, 2003, pp. 893-894. doi:10.1097/00006982-200312000-00039

[32] C. Eckardt, T. Eckert and U. Eckardt, "27-Gauge Twinlight Chandelier Illumination System for Bimanual Transconjunctival Vitrectomy," Retina, Vol. 28, No. 3, 2008, pp. 518-519. doi:10.1097/IAE.0b013e3181607a0f

[33] Y. Oshima, D. R. Chow, C. C. Awh, H. Sakaguchi and Y. Tano, "Novel Mercury Vapor Illuminator Combined with a 27/29-Gauge Chandelier Light Fiber for Vitreous Surgery," Retina, Vol. 28, No. 1, 2008, pp. 171-173. doi:10.1097/IAE.0b013e31814fb0d3

[34] R. Sorcinelli, "Surgical Management of Epiretinal Membrane with Indocyanine-Green-Assisted Peeling," Ophthalmologica, Vol. 217, No. 2, 2003, pp. 107-110. doi: $10.1159 / 000068556$

[35] A. K. Kwok, T. Y. Lai, W. W. Li, D. C. Woo and N. R. Chan, "Indocyanine Green-Assisted Internal Limiting 
Membrane Removal in Epiretinal Membrane Surgery: A Clinical and Histologic Study," American Journal of Ophthalmology, Vol. 138, No. 2, 2004, pp. 194-199. doi:10.1016/j.ajo.2004.03.013

[36] K. Kwok, T. Y. Lai, W. W. Li, D. T. Yew and V. W. Wong, "Trypan Blue- and Indocyanine Green-Assisted Epiretinal Membrane Surgery: Clinical and Histopathological Studies," Eye (London), Vol. 18, No. 9, 2004, pp. 882-888. doi:10.1038/sj.eye.6701359

[37] A. K. H. Kwok, T. Y. Lai and K. S. Yuen, "Epiretinal Membrane Surgery with or without Internal Limiting Membrane Peeling," Clinical \& Experimental Ophthalmology, Vol. 33, No. 4, 2005, pp. 379-385. doi:10.1111/j.1442-9071.2005.01015.x

[38] S. K. Gibran, B. Flemming, T. Stappler, I. Pearce, C. Groenewald, H. Heimann, P. Hiscott and D. Wong, "Peel and Peel Again," British Journal of Ophthalmology, Vol. 92, No. 3, 2008, pp. 373-377. doi:10.1136/bjo.2007.129965

[39] C. Haritoglou, A. Gandorfer, M. Schaumberger, S. G. Priglinger, A. J. Mueller, C. A. Gass and A. Kampik, "Trypan Blue in Macular Pucker Surgery: An Evaluation of Histology and Functional Outcome," Retina, Vol. 24,
No. 4, 2004, pp. 582-590. doi:10.1097/00006982-200408000-00012

[40] C. Haritoglou, K. Eibl, M. Schaumberger, A. J. Mueller, S. Priglinger, C. Alge and A. Kampik, "Functional Outcome after Trypan Blue-Assisted Vitrectomy for Macular Pucker: A Prospective, Randomized, Comparative trial," American Journal of Ophthalmology, Vol. 138, No. 1, 2004, pp. 1-5. doi:10.1016/j.ajo.2004.03.005

[41] D. Tognetto, S. Zenoni, G. Sanguinetti, C. Haritoglou and G. Ravalico, "Staining of the Internal Limiting Membrane with Intravitreal Triamcinolone Acetonide," Retina, Vol. 25 , No. 4, 2005, pp. 462-467. doi:10.1097/00006982-200506000-00011

[42] H. Enaida, T. Hisatomi, Y. Hata, A. Ueno, Y. Goto, T. Yamada, T. Kubota and T. Ishibashi, "Brilliant Blue G Selectively Stains the Internal Limiting Membrane/Brilliant Blue G-Assisted Membrane Peeling," Retina, Vol. 26, No. 6, 2006, pp. 631-636.

[43] H. Shimada, H. Nakashizuka, T. Hattori, R. Mori, Y. Mizutani and M. Yuzawa, "Double Staining with Brilliant Blue G and Double Peeling for Epiretinal Membranes," Ophthalmology, Vol. 116, No. 7, 2009, pp. 1370-1376. doi:10.1016/j.ophtha.2009.01.024 